\title{
Types of Constraints on Development: An Interactivist Approach
}

\author{
January 24th, 1991 \\ Robert L. Campbell \\ Mark H. Bickhard \\ User Interface Institute \\ IBM T. J. Watson Research Center \\ PO Box 704 \\ Yorktown Heights, NY 10598 \\ (914) 784-7722 \\ RLC at YKTVMH (bitnet); RLC at IBM.COM (internet) \\ Department of Psychology \\ Chandler-Ullmann Hall \#17 \\ Lehigh University \\ Bethlehem, PA 18015 \\ MHBO at NS.CC.LEHIGH.EDU (internet)
}




\begin{abstract}
The interactivist approach to development generates a framework of types of constraints on what can be constructed. The four constraint types are based on: (1) what the constructed systems are about; (2) the representational relationship itself; (3) the nature of the systems being constructed; and (4) the process of construction itself. We give illustrations of each constraint type. Any developmental theory needs to acknowledge all four types of constraint; however, some current theories conflate different types of constraint, or rely on a single constraint type to explicate development. Such theories will be inherently unable to explain important aspects of development.
\end{abstract}




\section{TYPES OF CONSTRAINTS ON DEVELOPMENT: AN INTERACTIVIST APPROACH}

\section{Constraints}

Some conception of constraint is fundamental to any account of psychological development. Accounts of developmental sequences are a familiar and widespread example (Flavell, 1972; Campbell \& Richie, 1983). Developmental stages are an even better known, though more controversial case. But constraints figure just as crucially in approaches to development that deny the existence of stages. No matter what processes of developmental construction are proposed, not all paths or orders or kinds of constructions are possible. Our concern here is to identify the major kinds of developmental constraints, and to explore the degree to which existing developmental theories acknowledge such constraints or are able to come to terms with them.

Our focus is on constraints that are inherent in the development of the individual, not genetic constraints on development generated in the phylogeny of the species. We have no intention of disparaging phylogenetic constraints, because they certainly operate, and govern, among other things, the capacities of human infants who are beginning to interact with their environments. But they are the object of a somewhat different inquiry (e.g., Bickhard, 1980a, in press-a). Attention needs to be drawn to the distinction between developmental versus phylogenetic constraints because a number of contemporary discussions of "constraints" tend to confuse the two categories. It is perfectly legitimate to propose that the course of first language learning, or the development of skills for manipulating and locating objects in space, are constrained by human pre-adaptations for constructing communicative action systems or for extracting invariances over spaces of possible manipulations. 
But is not enough to stop there, merely declaring that human beings are "biased" or "constrained" learners, and enumerate the biases, as Spelke (1990) does for object perception, or Markman (1990) does for the learning of nouns that refer to objects. It is necessary to account for the origin of such biases through the course of development if acquired, and as pre-adaptations through evolution, starting from a base of blind variation and selection (Bickhard, 1988), if innate. This sort of account is rare in developmental psychology generally, and is shunned outright by nativists.

Questions about the possible types of developmental constraints affect all accounts of development, regardless of their presuppositions or theoretical claims. We have found it useful, however, to approach this question from the standpoint of interactivism, because of the wide range of constraints that can be identified within this framework, including some that are usually ignored by other frameworks. Our examples of the different constraint types will come from a wide variety of developmental frameworks, and we will make some concluding comments about the power of interactivism and other frameworks to explicate the full range of developmental constraints disclosed by our inquiry.

\section{Interactivism and Constructivism}

Fundamentally, interactivism (Bickhard, 1980; Bickhard \& Richie, 1983; Campbell \& Bickhard, 1986) treats representation as interactive, not encoded. Representation is an aspect of functional systems, not a structure of elements. The interactive conception of representation, and arguments for the untenability of encoding-based approaches to representation, have been developed extensively elsewhere (see the above references, and Bickhard and Campbell, $1987,1989)$. Here our focus will be on the consequences of interactivism for 
constructive developmental processes, and for possible types of developmental constraints.

Interactivism forces a constructivist approach to development. Interactive systems cannot be transduced or induced from the environment. They must be constructed and tried to see if they work. Hence a variation and selection based process of construction is required (Bickhard, 1980; Campbell \& Bickhard, 1986; Bickhard \& Campbell, 1987).

There is not a completely open space of possible constructions. Specifically, the order of possible constructions -- what can be built on what -- is constrained in a number of different ways.

\section{Four Types of Constraint}

Given our theoretical positions regarding the nature of representation and constructive processes, we can distinguish four kinds of constraints:

1. what constructed systems are about

2. the representational or "aboutness" relationship itself

3. the nature of the systems being constructed

4. the processes of construction 


\section{What Constructed Systems are About}

Constraints of the first type are presupposed by many of the empirical research programs in developmental psychology, though the degree to which they are explicitly recognized varies across frameworks (see below). The prime examples are conceptual and task dependencies. Such dependencies arise because the nature of a concept or task intrinsically involves defining or subordinate concepts or tasks, thus constraining the order in which acquisition of the concepts or success on the tasks can occur.

For instance, success on Inhelder et al.'s (1974) class-compensation task, which calls for knowledge that $n$ items taken from one subset and added to the other leaves the total the same, presupposes knowledge of quantitative addition/subtraction (if two arrays differ by $n$, and $n$ is added to the lesser array, the arrays will then be equal). It also requires, more specifically, the additive composition of sets (knowing that a double array of $x+x$ is equal to an array of $(x-n)+(x+n)$; see Campbell, in press).

It is important to note, however, that presentational or definitional dependencies do not necessarily imply conceptual or task dependencies. Arithmetic can be defined in terms of set theory, but set theory need not be known in order to learn arithmetic. Calculus is taught in terms of limit theory, but it doesn't require that; it does require algebra (Henle \& Kleinberg, 1979; MacLane, 1986). Research into developmental sequences -- finding prerequisites -- involves developing and testing models of conceptual dependencies (Campbell \& Richie, 1983). For instance, the work of Cooper (1984) on number development outlines developmental sequences for numerical quantifiers like subitizing and operators like addition/subtraction; 
empirical orderings, like the fact that qualitative addition/subtraction precedes number conservation, are explained via conceptual dependencies (and, in some cases, task dependencies).

\section{The Representational Relationship Itself}

A concern that is specific to interactivism is developmental constraints that derive from the nature of the representational relationship itself -- the interactive knowing relationship. These constraints are intrinsic to knowing and representation. Take a system that knows its environment interactively, in terms of interactive differentiations and implicit definitions. The system itself may well have properties that would be worth knowing. Those properties of that first-level system knowing the environment, however, cannot be known by the system itself. They can, however, be known by a second-level system that knows the first, by interacting with it. So while the first-level system knows its environment, the system itself constitutes a potential environment for a second-level knowing system. The second-level knowing system will in turn have its own properties that could be known by a third-level system, and so on (Bickhard, 1980a; Campbell \& Bickhard, 1986).

There in fact is an unbounded hierarchy of potential levels of knowing. Now by definition, intrinsically, there can be nothing at a given knowing level unless there are already systems at the level just below it to be known. The levels of knowing are not just a hierarchy of potential things to be known, but also a hierarchy of potential development. The hierarchy can only be ascended one level at a time. The process of ascending the levels is essentially Piaget's (1977a, b) reflective abstraction, though the detailed specification of the process is different (Campbell \& Bickhard, 1986; see also below). 
In another part of the interactive framework, knowing interactions between adjacent levels are identified with consciousness. In this context, "consciousness" is understood in an explicitly reflective sense. It is one level knowing another level; in the minimal and fundamental case, it is level 2 knowing level 1 (see Bickhard, 1980a, for an evolutionary account of the nature of consciousness). Reflective consciousness is, in any case, quite different from consciousness understood as awareness, wakefulness, non-coma, sensory experience, working memory, activated encodings, or enlightenment.

\section{Logical Necessity and Knowing Levels}

Knowing level relationships can be illustrated with the general example of logical necessity. Logical necessity is a property of certain sorts of relationships, for instance, certain kinds of inferences (for a detailed account, see Campbell \& Bickhard, 1986; Bickhard, in press-a). Just because logical necessity is a property of certain sorts of relationships, the systems that interactively represent those relationships will not intrinsically represent the logical necessity of those relationships. Thus, the class-inclusion relationship can be understood at knowing level 2, whereas knowledge of the necessity of that relationship (that it must apply in all possible cases and cannot be altered by any addition or subtraction transformation -- Voelin, 1976; Markman, 1978) is

only possible at knowing level 3. (For a different illustration, see the treatment of four levels of deductive logic and metalogic by Moshman, 1990.)

\section{Logical Necessity, Structuralism, and Reflective Abstraction}

The knowing levels approach contrasts sharply with Piaget's structuralist conception, in which knowledge of logical necessity is an intrinsic aspect of fully equilibrated structures. It is impossible within Piaget's structural model of 
concrete and formal operations to distinguish between understanding a logical relationship like class inclusion and understanding that the relationship is necessary (in fact, Piaget himself never acknowledged that there was such a distinction). According to this model (e.g., Piaget, 1972), concrete operational Grouping I, a closed structure, is both sufficient for success on class inclusion inferences, and sufficient for an understanding of logical necessity. It must either automatically carry with it the understanding that those inferences are necessary, or some other (non-structural) explanation for understanding the necessity of class-inclusion must be sought.

There is much more to Piaget's oeuvre than structuralism, of course. Piaget's late work on consciousness, reflective abstraction, and necessity can certainly be taken to bear on the class-inclusion problem (as suggested by Chapman, personal communication, October 24, 1990), though Piaget never applied it himself. Specifically, the class-inclusion inference could be treated as the result of reflecting abstraction, whereas recognizing its necessity would be the result of reflected abstraction. The results of reflecting abstraction are typically unavailable to consciousness, whereas the results of reflected abstraction are conscious (Piaget, 1976, p. 346; 1977a, p. 303). Classinclusion inferences could be taken to arise through reflecting abstraction; knowledge of their necessity would then come about through a later reflected abstraction.

Unfortunately, it is difficult to see how this could be made to work. The knowing-levels model offers a clear definition of reflective abstraction, and relies on iterated reflective abstraction to explain understandings of logical necessity: reflection on classification procedures at level 1 produces classinclusion inferences at level 2, and reflection on those inferences at level 2 
produces understanding of their necessity at level 3. Piaget's reflected abstraction, however, is not an iteration of reflecting abstraction; it is reflecting abstraction plus consciousness. "We call the result of a reflecting abstraction 'reflected' when it has become conscious, regardless of developmental level" (Piaget, 1977a, p. 303, our translation). Reflected abstraction initially lags behind reflecting abstraction during the concrete operational period, then catches up with it (p. 312). During the formal operational period, reflected and reflecting abstraction happen simultaneously (p. 307). In other words, there is a décalage between reflecting and reflected abstraction during the concrete operational period, for which Piaget offers no explanation.

In fact, throughout Piaget's late work, structural accounts of necessity are simply juxtaposed with accounts based on reflective abstraction, with little or no attempt to reconcile them. Thus Piaget (1977b) can claim that reflective abstraction on meaningful implications produces local necessities prior to the constitution of concrete operational structures, while continuing to account for necessity in terms of properties of algebraic structures like their closure and their mathematical power. Although Piaget's late work on reflective abstraction touched on knowing-level or representational constraints on development, he did not succeed in disentangling reflective abstraction from his commitment to algebraic structures -- and to their equilibration as the basic developmental constraint (for an in-depth treatment of these issues, see further below, and Campbell \& Bickhard, 1986; Bickhard, 1988; Campbell, in press). 


\section{Other Dimensions in the Developmental Lattice}

It should also be noted that constraints on development based on the knowing relationship go beyond the hierarchy of knowing levels and their associated major stages. For instance, it is possible to reflect on reflective abstraction (something that we do whenever we discuss such constraints), and reflective abstraction is not at a particular knowing level -- it pertains to a relation between any two adjacent knowing levels. Indeed, from an interactivist standpoint, the hierarchy of knowing levels is just one dimension of a much richer structure of potential development, which includes metareflection (reflection about reflective abstraction) as a point along another dimension. The interactivist approach in fact generates an infinite dimensional lattice of potential development (Campbell \& Bickhard, 1986). Dimensions of development beyond the knowing-level hierarchy are not considered at all by other contemporary developmental frameworks.

\section{Constraints Within Knowing Levels}

Insofar as the knowing levels derive from the nature of representation, then all other constraints on development will hold within the framework of constraints based on the nature of the knowing relationship.

Some of these constraints, for instance, some conceptual dependencies, are also partly dependent on the knowing levels. Some concepts are about other concepts in a way that requires them to be at a higher knowing level. For instance, goals that are about other goals (that are satisfied by those goals, but are not ends toward which those goals are means), are conceptually dependent on those prior goals, but also require knowing level ascension (Campbell \& 
Bickhard, 1986). Similarly, mastery of properties of, and relations among, the class extensions of intensional terms (such as lemon or skunk) requires the prior mastery of those predicates -- a conceptual dependency. At the same time, mastery of defining conditions for those terms, and in particular, of defining conditions that incorporate explanatory "promissory notes" for unspecified underlying commonalities (in other words, treating them as natural kind terms) requires reflection and ascension to the next knowing level (Campbell \& Bickhard, in preparation).

\section{The Nature of the Systems Being Constructed}

Developmental frameworks make claims about the nature of the systems being constructed. These lead to a wide variety of express or implied claims about constraints, depending on how the nature of the systems being constructed happens to be viewed. If what is being constructed consists of subroutines, a subroutine hierarchy constraint is thought to be involved. If combinations of basic encodings or "primitive concepts" are being constructed, the combinatoric constraint on encodings applies. If systems of production rules are being constructed, then some sort of production rule constraint presumably applies. If algebraic structures are being constructed, then there are constraints on the equilibration of those structures.

\section{Subroutine Hierarchies}

A common constraint, foundational to most neo-Piagetian approaches, is that of subroutine hierarchies (e.g., Fischer, 1980; Case, 1985). Although the systems under construction are labeled in various terms, such as coordinated schemes (Case) or coordinated skills (Fischer), mathematically what is constructed is essentially subroutines (Campbell \& Bickhard, 1986). The claim 
that schemes or skills get coordinated in a standard order of complexity amounts to saying that the subroutine hierarchy imposes a developmental constraint: subroutines are built up one layer at a time, from the bottom layer up (the layers in Case's framework are described in detail below).

Such hierarchies of subroutine layers may well exist, but there is a problem with them as postulated sources of developmental constraints -subroutine hierarchies are not intrinsically constrained. If we regard it as a computer program, any subroutine hierarchy can be rewritten with a completely different hierarchal scheme. It can have different layers of subroutines, or no layers at all, or a hundred layers of subroutines, or the same number of layers as before but completely different principles of layering.

There is no intrinsic constraint on the succession of subroutine layers. Whatever constraints there are will have to come from some source outside the hierarchy.

Subroutines also raise the question of the relationship between functional routines and representational phenomena. How is it that subroutines have representational properties? How do they develop as representations? How could consolidations or reorganizations of subroutines, or of any other functional system, constitute new sources of representation? These are difficult questions. Current approaches that rely on subroutines, such as those of Fischer (1980) and Case (1985), do not address such questions.

In our treatment of constraints based on the knowing relationship, we pointed out that once the knowing-levels constraint is in place, other constraints can be seen to operate within it. This is as true of subroutine hierarchy constraints as of conceptual or task dependencies. Every knowing level may 
have subroutine hierarchies defined within it. Subroutine hierarchies, however, are not the same as knowing level hierarchies. Superordinate subroutines are not about their subordinates. For instance, the organization of eye-hand coordination space by coordinating kinesthetic with visual eye movement space, or the organization of kinesthetic space itself out of lower-level afferent and efferent processes, can be modeled with subroutine hierarchies (e.g., Powers, 1973). Moreover, such subroutine hierarchies involve genuine representational functions and not "mere" task and control flow. Yet there is no sense in which eye-hand coordination space could be said to be about kinesthetic space or visual eye movement space. The new organization is produced by control flow organization and coordination, not by representational "aboutness" relationships of any sort.

Within knowing levels, in any case, subroutine hierarchies are not the only possible principle of organization, nor necessarily the most interesting one. In a different architecture, such as parallel-processing systems that communicate via a common blackboard, there would be quite different constructive considerations.

\section{Combinations of Encodings}

Another presumed constraint based on the nature of the systems being constructed is the combinatorial constraint on the construction of encoded representations. The construction of representations is modeled as constructions out of lower-level representational elements. At the lowest level are representational atoms, such as features or semantic primitives. This generates a combinatoric constraint on what could possibly develop: only combinations of the basic atoms are possible. It generates a sequencing 
constraint in terms of the substructures of the representational elements being constructed. Developmental accounts that rely on combinatorial constraints are widespread (e.g., Clark, 1973; Kail \& Bisanz, 1982).

Now from the interactivist standpoint, encodings can function as a derivative form of representation, and complex encodings can be built from simple ones, though it is questionable how widespread such processes might be. But a general model of representational development based on combinatorial constraints is a straightforward application of encodingism, and is therefore subject to all of the arguments against encodingism (Bickhard, in press-c; Bickhard \& Richie, 1983). Genuine novelty is impossible under a universal combinatorial constraint. Indeed, Fodor (1981) has argued convincingly that the combinatorial constraint is too weak to allow much real learning, so most concepts would have to be built in at birth. The appearance of a developmental sequence in their emergence would have to be explained by recourse to extrinsic conditions that happen to "trigger" their expression at different times.

Interactivism is not forced to rely on the combinatorial constraint at all, because interactive representations are constructible from units that are not themselves representations (Campbell \& Bickhard, 1987; Bickhard, in press-b). The scope of any combinatorial constraint is bound to be narrow and local, and accounts of word learning or of the emergence of new conceptual or "declarative" knowledge -- to pick some fields in which the combinatorial constraint is often cited -- necessarily burst its bounds. 


\section{Production Rules}

A constraint related to the combinatorial constraint on encodings is involved in the use of production rules to model development (Klahr \& Wallace, 1976; Anderson, 1983; Wallace, Klahr, \& Bluff, 1987). Although Anderson (1983) draws a distinction between procedural and declarative knowledge, and puts production rules on the procedural side of the fence, they are nonetheless encodings, specifically, encoded rules: their antecedent conditions are specified in terms of encodings, they operate on encodings (usually symbols stored in working memory), and their actions usually consist of putting other symbols in working memory. The vocabulary of encoded symbols used to define the conditions of production rules is essentially fixed by the combinatorial constraint; simple combinations of old symbols are possible, but novel symbols that could figure in the conditions of new productions cannot emerge (Campbell \& Bickhard, 1990).

Production rules have the additional limitation of not being able to model all kinds of actions. They model singular actions only; they are not servomechanisms capable of indefinitely graded actions with feedback corrections. Nor is there any topology for interpolating or extrapolating solutions from problems that have already been solved. And they are vulnerable to general critiques of mental rules. Kripke (1982) has interpreted Wittgenstein (1958) as offering a general skeptical critique of mental rules: from the mere fact that a person's behavior can be described with a rule, there is no way of knowing whether the person is acting by following that rule or some other rule entirely. Whether Wittgenstein intended so strong an position is controversial (Baker \& Hacker, 1985; Chapman, 1987a), but the provenance of 
the argument is not important here. What is important is that, if the argument is valid, production rule models have no claim to explanatory adequacy or to psychological reality.

Let us now turn to the work that has been done on the modification of production rules and the acquisition of new ones. It has become clear to some researchers actively engaged in production system modeling, like Neches, Langley, and Klahr (1987) and VanLehn (1988), that the mechanisms so far proposed are incapable of accounting for the development of organization, reorganizations in development, or novel representations. As Neches et al. (1987, p. 32) point out, "some researchers (e.g., Anderson 1983) have asserted that mechanisms such as composition, generalization, and discrimination [of production rules] are sufficient to account for all learning... These processes...are by no means sufficient."

Anderson (1983), for instance, leans strongly on composition of productions (that is, habitualization of sequences of production rules). "For example, Lewis (1981) has documented differences between expert and novice solution methods for algebra expressions, and shown that the differences could not have been produced by composition. Lewis...[demonstrates] that the the procedures produced by a process of composition would not apply correctly in all cases. To ensure that a new procedure would work correctly, additional rules must be produced by some process other than composition" (Neches et al., 1987, p. 32). In fact, composition of production rules can be shown to mathematically insufficient to generate novel procedures or new knowledge in development (for additional exploration of the limits of composition, see Lewis, 1987). Composition is mathematically equivalent to habituation: it makes an 
already possible sequence of actions faster, but does not generate any new possible sequences. ${ }^{1}$

Additional mechanisms that have been proposed, such as generalization and differentiation of the encoded conditions of productions, are also inadequate to explain known reorganizations of procedures that occur in learning.

Another example of complex expert strategies appears in Hunter's (1968) analysis of the procedures employed by a "mental calculator," a subject with highly excep tional skills at mental arithmetic.... Some [skills] such as his large collection of number facts, might be explained in terms of [compositional] mechanisms... However, there are many aspects of the subject's per formance for which it is very difficult to see how syntactic learning mechanisms could have produced the observed results.

For instance, Hunter found that his subject's su perior ability to mentally solve large multiplication problems was due to a procedure that performed the component multiplications in left-to-right order while keeping a running total of the intermediate products. This contrasts to the traditional pencil-and-paper algorithm in which columns are multiplied right-to-left, with the subproducts written down and totaled afterward in order to compute the product. The left-to right procedure, which

\footnotetext{
${ }^{1}$ It might be objected that hierarchies of compositions yield recursion, and that therefore a system of production rules with a composition mechanism could have at least the computational power of recursive function theory. There are problems with this argument, however: (1) what would be the appropriate set of primitive functions for modeling cognition?; (2) would any set of primitive productions or primitive actions have sufficient power?; and (3) not all programs or system organization are recursive, and, more importantly, not all useful programs or system organizations are either.
} 
drastically reduced the working memory demands of any given problem, requires a massive reorganization of the control structure for the traditional multiplication procedure.

The reorganization involves much more than refinements in the rules governing when suboperations are performed. Such refinements could presumably be produced by generalization and discrimination mechanisms. However, producing this new procedure requires the introduction of new operations (or at least new goal structures), such as those involved in keeping a running total of the subproducts. Those new operations, and the control structure governing the sequence of their execution, require the introduction of novel elements or goals--something that generalization, discrimination, and composition are clearly not able to do. (Neches et al., 1987, pp. 32-33, our emphasis).

After considering some other examples, such as acquiring expertise in solving textbook physics problems, solving Tower of Hanoi problems, and using a computer graphics system, all of which appeared to involve generating new goals, Neches et al. (1987) concluded that

learning [in these examples] appears to involve reasoning on the basis of knowledge about the structure of procedures, and the semantics of a given procedure in particular [a point also made by Lewis, 1987]. In each of the examples we have considered, procedures were modified through the construction of novel elements rather than through simple deletions, additions, or combinations of existing elements. This leads us to believe there exist important aspects of learning that involve the use of both general and domain-specific knowledge about procedures. (p. 34) 
Now the development of knowledge about procedures is an instance of the knowing-levels constraint, not a constraint on the type of system being constructed. ${ }^{2}$ So to the inability of production rule models to account for novelties in development we must add the inability to account for knowing-level ascensions. On the whole, production rules are not an adequate account of what is being constructed, and production-rule-based constraints are unlikely to be satisfactory.

In general, contemporary theories tend to use constraints based on the types of systems under construction to cover too wide a territory: to account for developmental phenomena that involve constraints on the knowing relationship, or on the process of construction. We will give detailed examples below.

\section{The Process of Construction}

Constraints deriving from the process of developmental construction are patchily acknowledged by existing frameworks, but remain seriously underexplored. One subtype is constraints that reflect limitations on the resources that the constructions need to make use of: constraints on memory and processing resources are the best-known examples. Such constraints are valid in a general sense; having limited processing resources has to constrain how the human mind operates. The current employment of such constraints in developmental theories is problematic, though (see our discussion of Case's theory below).

2 It is a separate question whether all of the examples of learning covered by Neches et al actually requir ${ }^{* *} e$ knowledge about procedures (as opposed to learning heuristics and topologies). All that is needed for our argument is that some kinds of learning do. 
Another sort of constraint is limitations on the possible sorts of constructions that can be done. Fodor's (1983) conception of input modules and Gardner's (1983) intelligences can be understood in terms of constraints on what could be constructed. More exploration of these conceptions from a developmental standpoint is necessary in order for these constraints to be evaluated. It is clear, however, that there are big jumps in Fodor's (1983) reasoning: there is a jump from observing that functions like vision have become specialized in the course of evolution, to claiming that the visual system is an encapsulated "input module." There is an additional jump from the assertion of modular organization in the mind to the assertion of "epistemic boundedness": constraints on what can be represented. In particular, the jump to epistemic boundedness works only if it assumed that representation consists of foundational encodings and that each module has its own limited private stock of encodings (Bickhard \& Campbell, 1989).

Finally, constraints on developmental trajectories that derive from the nature of the constructive process, from the nature of learning, are to be expected and should be important. Such constraints are rarely proposed because they depend on articulated theories of developmental process, and these continue to be scarce.

Indeed, the current literature on constraints contains a number of examples of constraints that seem intended to be of this type, but which are not clearly differentiated from constraints based on what is known (type I) or constraints based on the type of system being constructed (type 3). For instance, Gelman (1990) claims that "principles implicit in preverbal counting mechanisms... account for infants' attention to stimuli in a number-relevant way... A skeletal set of counting and addition principles is available to support 
these kinds of early selective attention and the accrual of a relevant body of knowledge" (p. 83) Let's leave aside some questions about the specific proposals (does infants' ability to distinguish small numerosities really come from preverbal counting? can skeletal principles be anything but encodings?), and assume they are instances of real constraints. To what extent are these domain-specific constraints on the learning process - or local consequences of domain-general constraints on learning (see our discussion of Keil, 1990, below)? To what extent are they constraints that derive from what is known (for instance, possible prerequisite relations between quantifying items by counting them, primitive addition and subtraction operations, and later number abilities)? Because Gelman offers no account of the constructive process, there is no way to tell.

Newport (1990) argues persuasively for the existence of a sensitive period for first and second language learning: mastery of a language falls off noticeably with age of acquisition after age 7 . She concludes that maturational constraints on language learning must be involved. These would presumably be constraints on the process of language learning. However, after arguing against the decay of a Chomskyan "language faculty" with age the source of the sensitive period, she suggests that improvement in cognitive capacities with age may actually interfere with language learning, particularly the learning of morphology: "If children perceive and store only component parts of the complex linguistic stimuli to which they are exposed, while adults more readily perceive and remember the whole complex stimulus, children may be in a better position to locate the components" (p. 24). Newport's analysis is interesting, and might well be correct. However, it posits an increasing capacity constraint, rather like Case's (1985), and not a constraint based on the nature of 
the learning process. Again, there is a lack of clarity about constraint types, traceable in part to a lack of clarity about developmental processes.

It is also worth noting that constraints based on the knowing relationship do not figure in the work of Gelman and Newport, nor in the previously cited work of Spelke (1990) or Markman (1990). Nor does a thoughtful commentary on them by Keil (1990) ever mention type 2 constraints. In fact, Keil (1990), while arguing against "global stage views," does not discuss any examples of what stage theorists would consider to be stage changes; such a discussion might have introduced some instances of knowing-level constraints.

Keil's (1990) rejection of global stage views deserves closer scrutiny in the context. Keil, like many others in developmental psychology, takes the existence of specialized expert learning strategies as evidence against a domain-general learning process. That is, because people who know a lot in a domain learn better, and perhaps differently, than people who know little in that domain, and because this differential learning effect may itself be domainspecific, it is assumed that the relevant constraints on learning have to be domain-specific and not domain-general. A global stage model, which relies on domain-general constraints, is forced to predict uniform global shifts in the form or organization of representation that cut across domains.

This is an invalid argument. Any form of constructivism that is recursive that uses the previous results of its own constructions - is a counterexample to it. A recursive constructive process could be domain-general as a process, and at the same time manifest domain-specific historicity. In a recursive constructive process, early constructions would alter the form and increase the effectiveness of later constructions. Domain-specific historicities of learning and development 
are important, but are not the same as domain-specific learning processes. The counterexample is even stronger in the case of metarecursive constructivism, in which procedures for variation and selection are themselves subject to variation and selection (i.e., there is genuine learning to learn).

This point has been missed because inductivist learning theories are not recursive, and Piaget's equilibration, while recursive, was not developed in a domain-specific direction by Piaget, nor by most Piagetians (Feldman, 1980, is a distinct exception). This would have been difficult for Piaget, in any case, because of his rejection of a variation and selection conception of development (Bickhard, 1988). And, to our knowledge, interactivism is alone in propounding metacursive developmental processes (Bickhard, in press-a).

One clear example of a process based (and domain-general) constraint on trajectories, however, is Simon's (1969) argument that development will normally be possible only through "nearby points of stability." This can be generalized into a constraint of differentiation, specialization, and autonomization on the development of subsystems (Bickhard, 1980b). Further constraints will, no doubt, emerge from a careful examination of the elaboration of heuristics for problem solving and problem identification, the development of heuristics for constructing such heuristics, the differentiation of domains within and out of other earlier domains, the unfolding of critical principles for the exclusion or refutation of hypotheses, and other aspects of the constructive process (Bickhard, 1988, 1991, in press-b). Except for the pioneering work by Karmiloff-Smith (1986) on internal reorganizations in the course of language development and map-drawing and by Feldman (1980) on the development of expertise, very little attention has been paid to learning heuristics and their development. Learning heuristics and critical principles will need to be a major 
concern, not only in the future development of interactivism, but for developmental psychology as a whole.

Since contemporary developmental frameworks do not recognize all four kinds of constraints that we have discussed above, they tend to conflate types of constraints, expecting one kind to do the work of another. We have already mentioned some examples in our treatment of constraints on the constructive process. Among the examples we will now consider are Piaget's (1975/1985) equilibration, Rozin's (1976) accessing, Smith, Carey, and Wiser's (1985) view of conceptual development as the differentiation of preexisting components, and Case's (1985) combination of subroutine hierarchy and capacity constraints.

\section{Conflating Types of Constraints}

\section{Equilibration}

Piaget's conception of equilibration mixes up constraints of the the second, third, and fourth type. Piaget (1975/1985; 1977a, b; 1981/1987) never succeeded in fully distinguishing equilibration from reflective abstraction. Equilibration involves constraints on the systems being constructed -- for Piaget, cognitive structures. It involves a tendency toward closed, reversible, fully compensated algebraic structures. Reflective abstraction, on the other hand, makes properties that were implicit in the functioning at one level explicit at the next level -- it is an instance of the knowing-level constraint.

In our account of the knowing levels above, we referred to a good example of this conflation. Piaget attempted to define logical necessity as the product of reflective abstraction from procedural roots on the one hand, and as 
the result of structural closure on the other. These approaches are incompatible with each other; a structural account of necessity fails to distinguish having an understanding that is in fact necessary from knowing that it is necessary (Campbell \& Bickhard, 1986; Bickhard, in press-b). Piaget's account of necessity in terms of structural closure leads him to account for the ability to perform a level 2 class-inclusion inference by positing a structurally closed concrete operational grouping. But no higher-order structure is available to account for recognizing the (level 3) logical necessity of the class-inclusion relationship. Nor, as we showed above, is the ad hoc distinction between reflecting and reflective abstraction helpful here. Hence the perplexity that persists among Piagetians: is the level 2 class-inclusion inference "logical" or "empirical"? (Voelin, 1976; Markman, 1978; Josse, 1984; Campbell and Bickhard, 1986).

Another sign of conflation between constraint types is Piaget's insistence that "physical" or "empirical" abstraction (e.g., 1977a) is extremely limited in scope (to "inductive" but not "completive" generalization) and cannot produce any novelties in development. In consequence, Piaget is forced to posit reflective abstraction as early as infancy, and to improvise the troublesome distinction between reflecting abstraction (the stripped down version without the consciousness option) and reflected abstraction (which comes complete with consciousness). In fact, he cannot draw any principled distinction between reflective abstraction and equilibration, which he also claims must be opposed to mere inductive "learning". Once again, what Piaget has done is to mix up a constraint based on what is constructed (the equilibration of cognitive structures) with a constraint based on the knowing relationship (reflective abstraction). To compound matters, he has also conflated equilibration with 
constraints on the process of construction (for a detailed comparison of equilibration with a variation-and-selection model of learning, see Bickhard, 1988). From an interactivist standpoint, there is no such thing as induction, and processes of variation and selection learning are quite capable of producing developmental novelties. To assert that reflective abstraction is necessary for developmental novelties is a fundamental error, albeit one with impeccable Piagetian credentials.

\section{Accessing}

A cruder conflation of the same general type is the appeal by some theorists (e.g., Brown, 1982; Gelman \& Baillargeon, 1983; Greeno, Riley, \& Gelman, 1984) to a process called accessing as the source of developmental advances. The root metaphor for accessing (Rozin, 1976) is connecting, and passing information between, parts of the brain that serve specialized functions. Thus, accessing is a form of learning, and a weak one at that (connecting up parts of the brain has no more power than associationism, which is inadequate to account for most of the constructions possible in learning. If such channels are conceived as channels for passing "information," rather than just for passing activation, they might be construed as having more power than associationism, though still not nearly enough: Could accessing create new subroutines out of

old ones, for instance? Could it create subroutines at all? Accessing is a vague example of a constraint deriving from the nature of the systems being constructed.

However, under the rubric of "accessing to consciousness," accessing is used to account for making implicit knowledge explicit. Again, however, such a transition is an instance of the knowing-level constraint. Accessing is being 
used to do the work of reflective abstraction when, in fact, it is an instance of a different type of constraint, and lacks the power to do what reflective abstraction does (Campbell \& Bickhard, 1986).

It might be argued that there two distinct kinds of accessing, the associative variety and the reflective variety, and while the use of a single term for these different constraint types is misleading, the underlying concepts are indeed different. The appeal to accessing by theorists who reject both Piagetian structuralism and anything like knowing levels (e.g., Gelman \& Baillargeon, 1983; Greeno et al., 1984) makes this interpretation unlikely. The confusion is conceptual and not merely terminological.

We have considered two examples of conflation between constraints based on the nature of the system being constructed and the knowing-levels constraint. But as we showed in the case of equilibration, such conflations frequently also involve the underdeveloped fourth category, constraints based on the nature of the constructive process. This is particularly so when, as sometimes happens, one constraint type out of the four is taken to be the master constraint, sufficient to account for whatever interesting properties the course of development might have. "Theory change" models of development and Case's neo-Piagetian model both provide examples of these broader conflations.

\section{Combinatorial Constraints and Theory Change}

Some models reduce cognitive development to the development of "concepts" -- frequently, as embedded in "theories" -- and treat concepts as complexes of primitive features or "components." Smith, Carey, and Wiser (1985) treat concepts of weight, density, and volume this way: "An undifferentiated concept has components which will become specific to each of 
its descendants. Yet as parts of the undifferentiated concept, those components make up an articulated, integrated whole. The lack of distinction between those components makes the concept inadequate in some contexts, but that is true of any concept in any theory." (Smith et al., 1985, p. 180). "Children conflate the components heavy and heavy for size in one weight concept and...develop distinct weight and density concepts as they are reconceptualizing their concept of material kinds." (p. 227). For the concepts of weight and density to be differentiated from one another, they have to be preformed as "components" of an undifferentiated weight concept. But whence come the components? They are treated as irreducible atoms.

This approach, then, is not so implicitly committed to the the combinatorial constraint on encodings, a type of constraint on the nature of systems constructed. The combinatorial constraint is particularly weak; as Fodor (1981) has shown, very little concept learning, and no genuine novelty, is possible if only combinations of primitive encodings are possible. Instead, virtually all concepts must be built in at birth, and that still leaves their biological evolution a mystery (Campbell \& Bickhard, 1987). With only the combinatorial constraint, it is impossible to account for "radical theory change" in cognitive development, as Smith et al. wish to do. It does not help to insist that concepts only function in the context of a "theory" if each concept is built from a fixed stock of components, whose origin can't be accounted for. Radical theory change involves the development of novel "components," not just the repackaging of old ones. Knowing-level ascensions, like those that occur in the development of natural kind categories, or in the recognition that one has a theory of weight, are also beyond the reach of such an account (Campbell \& Bickhard, in preparation). 


\section{Subroutine Hierarchies and Capacity Constraints}

Another style of model that acknowledges an inadequate range of constraints is the neo-Piagetian stage model, exemplified by the work of Fischer (1980) and Case (1985). Case's model, for instance, generates a set of stages, and attempts to account for all of cognitive development, using a subroutine hierarchy constraint and a capacity constraint (on the amount of short term storage space or STSS). The subroutine constraint is a constraint derived from the nature of the system being constructed; the capacity constraint pertains to the process of construction itself. We will focus here on the subroutine constraint, because it dictates the form and the nature of developmental stages for Case. The subroutine hierarchy constraint grounds Case's claim to have a constructivist model, insofar as processes that build more elaborate subroutines are considered adequate to account for transitions between major stages. (Under the capacity constraint that he prefers on empirical grounds, the "common ceiling model," which posits a new kind of STSS unit for each major stage, Case would be forced to abandon a subroutine-based account of ascension to the next major stage, and stage ascension would become purely maturational - see Bickhard, Cooper, Mace, 1985.)

In Case's model, there are four major stages: sensorimotor operations, relational operations, dimensional operations, and vectorial operations. (For reasons unstated, the sequence terminates with vectorial operations, which are roughly equivalent to Piaget's formal operations.) Within each stage is a fourstep substage sequence that reflects the complexity of the subroutines constructible at that substage -- specifically the number of levels of subroutines that can be coordinated: 
(0) operational consolidation

(1) unifocal coordination

(2) bifocal coordination

(3) elaborated coordination

The next subroutine coordinations beyond elaborated coordination constitute substage 0 of the next major stage; in principle, subroutines at higher stages can always be unfolded into a complex structure of lower-stage subroutines.

We have already described the general problems of reliance on a subroutine constraint: subroutine complexity is arbitrary, and the representational significance of subroutine hierarchies is unclear. When taken as the central developmental constraint, the subroutine hierarchy approach generates additional problems. Among these are an inability to deal with reflective abstraction, consciousness, or ascent from implicit to explicit knowing -- these require a knowing-levels constraint. And indeed, Case (1985) never mentions consciousness or reflective abstraction as developmental issues.

But there are two additional problems: the assumption that each stage has the same number of substages, and the underlying assumption that the same constraint produces both the substage sequence and the major stage sequence. Consider first the assumption that a common underlying constraint generates both major stages and sub- stages. Logically, it should be impossible for major stages and their substages to be based on the same kind of constraint. Stage kinds are defined by the constraint kinds that generate them, and the same constraints will generate stages of the same sorts. Major stages are based on the knowing-levels constraint; if the knowing-levels 
constraint were found to differentiate stages within what had been thought to a major stage, that would be grounds for redefining the major stages. Any substages within a major stage must be based on a different kind of constraint, such as a process-related constraint on learning, or systematic conceptual dependencies of some kind.

Moreover, even if substages based on a subroutine hierarchy did not suffer from arbitrary level distinctions (discussed above), there is nothing about subroutine analysis that mandates the same number of substages in every stage, or in every domain in which that stage development can occur. Not all abilities that develop within a stage can be modeled uniformly in terms of four levels of subroutine elaboration. How about an ability that only goes through only two subroutine coordinations within a knowing-level stage? How about one that goes through five? How many subroutine coordinations does class inclusion or conservation of liquid volume or social perspective-taking go through? Can variations in the number of coordinations be ruled out a priori?

In general, a constraint that makes all developmental sequences within a stage have the same number of steps, though not strictly impossible, is highly unlikely. Different sequences in different domains may go through a different number of levels within a stage, and the constraints that go into defining the levels may not be the same across domains. A uniform number of "horizontally structured" substages within a single knowing-level stage is therefore very unlikely, and a uniform number of substages across all possible knowing-level stages all the more so.

\section{Combining Structuralism with Functionalism}


Case's (1985) approach to stages is an instance of a popular trend in developmental psychology: attempting a synthesis of Piagetian structuralism and information-processing functionalism. Such a synthesis is widely recommended by structuralists seeking to remedy the inability of algebraic structures, which are mathematically destined to be static, to account for the processes involved in problem solving (Inhelder \& Piaget, 1979; Cellérier, 1979; Beilin, 1983; Kuhn, 1983). (This assimilation has not been reciprocal; information-processing functionalists, e.g., Wallace, Klahr, \& Bluff, 1987, and Chi, Glaser, and Farr, 1988, consider Piaget to be the author of tasks, not of a theory. They ignore Piagetian structuralism or dismiss it as theoretically uninteresting.)

The first question to ask about such a synthesis is whether it can be done. It is widely assumed that the assumptions of structuralism and functionalism are compatible. Yet there are reasons for doubt. For instance, any synthesis of structuralism and functionalism must reconcile the inertness of "declarative" structures (which simply have processes operate on them) in information-processing views with the biologically intrinsic activity and selforganization that Piaget (1967/1971; Gardner, 1973) wanted structures to have. Existing attempts, whether they presume in favor of active structures (Inhelder \& Piaget, 1979) or inert ones (Boden, 1979), do not address this question clearly.

But let's suppose that structuralism and functionalism are compatible, and that the synthesis under consideration really brings together the strengths of both approaches: the systematic, holistic description of abilities, on the one hand, and the detailed accounts of heuristic problem solving, on the other. To combine the strengths of structuralism and information processing will take a deeper appreciation of information-processing conceptions than has been 
characteristic of neo-Piagetian attempts. NeoPiagetians (e.g., Case, 1985) have made rather superficial borrowings from information-processing approaches -- primarily countable indices of problem complexity, such as subroutines and working memory units. At times (e.g., Chapman, 1987b), the neo-Piagetian approach appears to be merely attaching a functionalist "performance component" to a structural "competence model" (for a critique of this type of maneuver, see Campbell and Bickhard, 1986). By contrast, researchers in the Genevan functionalist tradition (Inhelder et al., 1976; Blanchet, 1980; Metz, 1985; Karmiloff-Smith, 1986) have made detailed analyses of the procedures that children use to solve problems, and of the possible mechanisms for the development of procedures and structures over time.

Even if combining structuralism and functionalism piles strength on strength, such a combination cannot provide all four types of developmental constraint. As we have seen, equilibration in structuralist models is a constraint on the type of system being constructed. In functionalist models, subroutine hierarchies and production rule layerings are also constraints on the type of system being constructed; working-memory capacity restrictions are constraints on the processes of construction. Notably absent from both approaches are constraints based on the knowing relationship. In consequence, neither structuralism nor functionalism can explicate consciousness or reflective abstraction; no combination of the two can do so either. Neither approach has made much headway with constraints based on the process of construction, and the combination of the two is unlikely to do better.

\section{Are Constraints Just a Matter of Transition Mechanisms?}


Regularities in the course of development, including regularities of the form of sequences and stages, can be imposed by any or all of the four types of constraints that we have described. What is important to recognize is that the first three of these types of constraints -- 1) what constructed systems are about, 2) the representational or "aboutness" relationship itself, and 3) the nature of the systems being constructed -- will impose sequential, and even stage-like, regularities on development no matter what the processes of development are. No process of development could overcome the necessity of knowing algebra before calculus, nor skip levels of reflective knowing, nor construct a completed whole before a necessary part was available. Such types of developmental regularities are independent of the actual processes of developmental construction, and, conversely, models of the processes of development will not be sufficient to explain them.

The significance of this point is that there are kinds of explanation that cannot be accommodated by the restriction to efficient causal kinds of explanation that psychology has inherited from logical positivism and behaviorism. Correspondingly, these constraints are difficult to think about for anyone still mired in the logical positivist heritage. On the surface it might appear that psychology escaped that heritage long ago with Piaget and Chomsky and computer models, but the logical positivist tradition is still deeply embedded, often unknowingly, in the presuppositions and manners of thought of psychology and psychologists (Bickhard, submitted; Bickhard, Cooper, \& Mace, 1985; Kitchener, 1983).

In developmental psychology, one vestigial trace of logical positivism is a tendency not to credit explanations of developmental regularities unless they are explanations in terms of efficient causes. With the decline of behaviorism 
and associationism, this is often interpreted to mean: in terms of developmental constructive processes. This tendency, we should note, is certainly not universal. Fischer and Case offer explanations of developmental regularities in terms of subroutine hierarchy constraints, and although we have argued that this type of model has other problems, it constitutes a partial exception. Keil's model of regularities in conceptual development deriving from intrinsic constraints in the very nature of concepts, although it has its own distinct difficulties (Keil, 1984), is a clear example of a non-causal form of explanation (Keil, 1979, 1981), and Keil's (1990) survey of a number of proposals about constraints strongly implies the legitimacy of explanations without recourse to efficient causes. But there is no general sense in this work of the distinction between process or causally based explanations, on the one hand, and explanations by constraint, on the other, nor of other types of explanations (Campbell \& Bickhard, 1986).

On the other hand, there are numerous examples of overly narrow restrictions on valid forms of explanation. Brainerd (1978) has claimed that Piaget's stages will be explanatory only when given an efficient causal base (Bickhard et al., 1985). Piaget himself "acknowledged" that his model is not fully explanatory because it does not have a causal ground (Piaget, 1985, pp. 147148; Chapman, 1988, pp. 338-340). Information-processing approaches, when they undertake to treat development at all, do so only in terms of proposed change processes (Klahr \& Wallace, 1976; Klahr et al., 1987; Sternberg, 1984; VanLehn, 1988). In fact, as Thornton (1987) has pointed out, whenever production system modelers notice a difference between beginning and end states in a binary comparison, they posit a developmental process that produces just that difference. Other forms of constraint, as well as 
developmental processes with additional intermediate steps, could as easily be responsible for the observed differences.

As philosophers of science from Aristotle (1941) to Harré and Madden (1975) have sought to remind us, there are other kinds of valid explanations besides efficient causal explanations. Psychology will remain conceptually hobbled so long as it does not acknowledge and explore a differentiated and articulated field of possible kinds of explanations for the varied phenomena in its domain. Once again, developmental psychologists need to consider all four kinds of developmental constraints, and to make sure that their frameworks can deal with all four of them.

\section{Conclusion}

We have shown how the interactivist approach to development is inherently constructivist, and how it supports a framework of types of constraints on development. The four constraint types are based on: (1) what the constructed systems are about; (2) the representational relationship itself; (3) the nature of the systems being constructed; and (4) the process of construction itself. We have given illustrations of each constraint type. Any developmental theory needs to acknowledge all four types of constraint; however, some current theories conflate different types of constraint, or rely on a single constraint type to explicate development. Such theories will be inherently unable to explain important aspects of development.

Some comparisons between interactivism and other kinds of developmental frameworks are worth making at this point. We have argued that interactivism is superior to other developmental frameworks in its ability to recognize all four kinds of developmental constraints, and in its ability to catch 
conflations of different kinds of constraints. This is particularly the case with constraints deriving from the representational relationship, which other theories either ignore or confuse with rather different kinds of constraints. The critiques of Rozin's accessing and Piaget's equilibration as confusions of representational constraints with constraints on the systems being constructed cannot be made within those frameworks, or within any of their rivals except interactivism. Our point about the independence of constraints based on what developmental systems are about from the nature of specific developmental processes is also very difficult to make outside the interactivist framework.

We would argue that interactivism has clear advantages over other frameworks at a metatheoretical level -- at conveying what a developmental theory must be able to do to be adequate. For instance, it is clear that there are examples of knowing-level ascension, and any adequate developmental theory must be able to account for them as such. Because interactivism can account for knowing-level ascensions, and other frameworks either make them impossible or offer no clear account of them, interactivism is to be preferred.

But the difficulties of interactivism should not be minimized. The knowing-levels model makes it easy to identify understanding the necessity of class-inclusion inferences as the product of reflective abstraction, but the knowing levels per se do not specify how classes are represented, what class inclusion means within an interactive system, or by what precise route the system comes to recognize that the class-inclusion relationships on which its inferences depend cannot be altered. And the rejection of encodingism makes specific models of such phenomena harder to construct. The theorist cannot merely take a formal description of possible class-inclusion inferences, in the guise of coordinated classification subroutines or class-addition groupings, and 
conclude that children solve these problems by acquiring isomorphic mental structures. That is an encoding-based assumption, which cannot be true in general, and is unlikely to be helpful in particular (even if encodings are being used, it has to be shown how they are interpreted, and how the ability to interpret them originated). Instead, the theorist has to directly confront the underlying representational questions, and interactive accounts of how objects, classes, etc. are represented are still in their infancy (Bickhard, 1980b; Campbell and Bickhard, 1986, in preparation).

The interactivist response to these difficulties is that they must be faced anyway: that accounts of development that treat representations as encoded are confusing descriptions of possible task accomplishments with explanatory models of how they are accomplished. And to make headway in developmental psychology, we must tackle the explanatory questions. From the interactivist perspective, developmental psychology is a richer enterprise than in the prevailing accounts, but it is also a considerably more challenging one.

\section{Acknowledgements}

This article is fully collaborative. Portions were previously presented at the biennial meeting of the Society for Research in Child Development, Baltimore, April 23, 1987, and the annual meeting of the Jean Piaget Society, Philadelphia, June 2, 1988. Thanks to Michael Chapman, Len Breslow, and an anonymous reviewer for comments on previous versions. 


\section{REFERENCES}

Anderson, J. R. (1983). The architecture of cognition. Cambridge: Harvard University Press.

Aristotle. (1941). Metaphysica. In R. McKeon (Ed.), The basic works of Aristotle (pp. 681-926). New York: Random House.

Baker, G. P., \& Hacker, P. M. S. (1985). Scepticism, rules, and language. Oxford: Blackwell.

Beilin, H. (1983). The new functionalism and Piaget's program. In E. K. Scholnick (Ed.), New trends in conceptual representation: Challenges to Piaget's theory? (pp. 3-40). Hillsdale, NJ: Erlbaum.

Bickhard, M. H. (1980a). A model of developmental and psychological processes. Genetic Psychology Monographs, 102, 61-116.

Bickhard, M. H. (1980b). Cognition, convention, and communication. New York: Praeger.

Bickhard, M. H. (1988). Piaget on variation and selection models:

Structuralism, logical necessity, and interactivism. Human Development, 31, 274-312.

Bickhard, M. H. (1991). Topologies of learning and development: An unsolved problem. Unpublished manuscript, Departments of Philosophy and Psychology, Lehigh University, Bethlehem, PA. 
Bickhard, M. H. (in press-a). A prelogical model of rationality. In L. P. Steffe (Ed.), Epistemological foundations of mathematical experience. New York: Springer.

Bickhard, M. H. (in press-b). The import of Fodor's anticonstructivist argument. In L. P. Steffe (Ed.), Epistemological foundations of mathematical experience. New York: Springer.

Bickhard, M. H. (in press-c). How Does the Environment Affect the Person? In L.T. Winegar, J. Valsiner (Eds.) Children's Development within Social Contexts: Metatheoretical, Theoretical and Methodological Issues. Erlbaum.

Bickhard, M. H. (submitted). Myths of science. Manuscript submitted for publication.

Bickhard, M. H., \& Campbell, R. L. (1989). Interactivism and genetic epistemology. Archives de Psychologie, 57, 99-121.

Bickhard, M. H., Cooper, R. G., Jr., \& Mace, P. G. (1985). Vestiges of logical positivism: Critiques of stage explanations. Human Development, 28, 240-258.

Bickhard, M. H., \& Richie, D. M. (1983). On the nature of representation: A case study of James J. Gibson's theory of perception. New York: Praeger. 
Blanchet, A. (1980). Étude génétique des significations et des modèles utilisés par l'enfant lors des solutions de problèmes [Developmental study of the meanings and models used by children during problem solving]. Genève: Imprimerie Nationale.

Boden, M. A. (1979). Piaget. Glasgow: Fontana.

Brainerd, C. J. (1978). The stage question in cognitive-development theory. Behavioral and Brain Sciences, 1, 273-313.

Brown, A. L. (1982). Learning and development: The problems of compatibility, access, and induction. Human Development, 25, 89-115.

Campbell, R. L. (in press). Does class inclusion have mathematical prerequisites? Cognitive Development.

Campbell, R. L., \& Bickhard, M. H. (1986). Knowing levels and developmental stages. Basel: Karger.

Campbell, R. L., \& Bickhard, M. H. (1987). A deconstruction of Fodor's anticonstructivism. Human Development, 30, 48-59.

Campbell, R. L., \& Bickhard, M. H. (1990). If human cognition is adaptive, can human knowledge be encoded? IBM Research Report RC16345. Yorktown Heights, NY: IBM.

Campbell, R. L., \& Bickhard, M. H. (in preparation). Knowing levels and the development of natural kind categories: Interactivism, structuralism, and nativism. 
Campbell, R. L., \& Richie, D. M. (1983). Problems in the theory of developmental sequences: prerequisites and precursors. Human Development, 26, 156-172.

Case, R. (1985). Intellectual development: Birth to adulthood. Orlando: Academic Press.

Cellérier, G. (1979). Structures cognitives et schèmes d'action [Cognitive structures and action schemes]. Archives de Psychologie, 47, 87-122.

Chapman, M. (1987a). Inner processes and outward criteria: Wittgenstein's importance for psychology. In M. Chapman \& R. A. Dixon (Eds.), Meaning and the growth of understanding (pp. 103-127). New York: Springer.

Chapman, M. (1987b). Piaget, attentional capacity, and the functional implications of formal structure. In H. W. Reese (Ed.), Advances in Child Development and Behavior (Vol. 20, pp. 289-334). New York: Academic Press.

Chapman, M. (1988). Constructive evolution: Origins and development of Piaget's thought. Cambridge: Cambridge University Press.

Chi, M. T. H., Glaser, R., \& Farr, M. (Eds.). (1988). The nature of expertise. Hillsdale, NJ: Erlbaum.

Clark, E. V. (1973). What's in a word? On the child's acquisition of semantics in his first language. In T. E. Moore (Ed.), Cognitive development and the acquisition of language. New York; Academic Press. 
Cooper, R. G., Jr. (1984). Early number development: Exploring number space with addition and subtraction. In C. Sophian (Ed.), Origins of cognitive skills (pp. 157-192). Hillsdale, NJ: Erlbaum.

Feldman, D. H. (1980). Beyond universals in cognitive development. Norwood, NJ: Ablex.

Fischer, K. W. (1980). A theory of cognitive development: The control and construction of hierarchies of skills. Psychological Review, 87, 477-531.

Flavell, J. H. (1972). An analysis of cognitive-developmental sequences. Genetic Psychology Monographs, 86, 279-350.

Fodor, J. (1981). The present status of the innateness controversy. In J. Fodor (Ed.), RePresentations (pp. 257-316). Cambridge: MIT Press.

Fodor, J. (1983). The modularity of mind: An essay on faculty psychology. Cambridge, Mass.: MIT.

Gardner, H. (1973). The Quest for Mind. Chicago.

Gardner, H. (1983). Frames of mind. New York: Basic.

Gelman, R. (1990). First principles organize attention to and learning about relevant data: Number and the animate-inanimate distinction as examples. Cognitive Science, 14, 79-106.

Gelman, R., \& Baillargeon, R. (1983). A review of some Piagetian concepts. In J. H. Flavell \& E. M. Markman (Eds.), Handbook of child psychology, vol. 3: Cognitive development (pp. 167-230). New York: Wiley. 
Greeno, J. G., Riley, M. S., \& Gelman, R. (1984). Conceptual competence and children's counting. Cognitive Psychology, 16, 94-143.

Harré, R., \& Madden, E. J. (1975). Causal powers. Totowa, NJ: Rowman \& Littlefield.

Henle, J. M., \& Kleinberg, E. M. (1979). Infinitesimal calculus. Cambridge, MA: MIT Press.

Hunter, I. M. L. (1968). Mental calculation. In P. C. Wason \& P. N. JohnsonLaird (Eds.), Thinking and reasoning. Baltimore: Penguin.

Inhelder, B., Ackermann-Valladão, E., Blanchet, A., Karmiloff-Smith, A., KilcherHagedorn, H., Montangero, J., \& Robert, M. (1976). Des structures cognitives aux procédures de découverte [From cognitive structures to discovery procedures]. Archives de Psychologie, 44, 57-72.

Inhelder, B., \& Piaget, J. (1979). Procédures et structures [Procedures and structures]. Archives de Psychologie, 47, 165-176.

Inhelder, B., Sinclair, H., \& Bovet, M. (1974). Learning and the development of cognition. Cambridge, MA: Harvard University Press.

Josse, P. (1984). Classes ou collections? Étude de la résolution entre 5 et 11 ans du problème "dit d'inclusion" [Classes or collections? A study of the solution by 5 to 11-year-olds of the 'class-inclusion' problem]. Paris: Éditions du Centre National de la Recherche Scientifique.

Kail, R., \& Bisanz, J. (1982). Information processing and cognitive development. In H. W. Reese (Ed.), Advances in child development and behavior (Vol. 17). New York: Academic Press. 
Karmiloff-Smith, A. (1986). From meta-processes to conscious access:

Evidence from children's metalinguistic and repair data. Cognition, 23, 95-147.

Keil, F. C. (1979). Semantic and conceptual development. Cambridge: Harvard University Press.

Keil, F. C. (1981). Constraints on knowledge and cognitive development. Psychological Review, 88, 197-227.

Keil, F. C. (1984). Mechanisms in cognitive development and the structure of knowledge. In R. J. Sternberg (Ed.), Mechanisms of cognitive development. New York: Freeman.

Keil, F. C. (1990). Constraints on constraints: Surveying the epigenetic landscape. Cognitive Science, 14, 135-168.

Kitchener, R. F. (1983). Changing conceptions of the philosophy of science and the foundations of developmental psychology. In D. Kuhn \& J. Meacham (Eds.), On the development of developmental psychology. Basel: Karger.

Klahr, D., Langley, P., \& Neches, R. (Eds.) (1987). Production system models of learning and development. Cambridge: MIT Press.

Klahr, D., \& Wallace, J. G. (1976). Cognitive development: An information processing view. Hillsdale, NJ: Erlbaum.

Kripke, S. A. (1982). Wittgenstein on rules and private language. Cambridge, MA: Harvard University Press. 
Kuhn, D. (1983). On the dual executive and its significance in the development of developmental psychology. In D. Kuhn \& J. A. Meacham (Eds.), On the development of developmental psychology. Basel: Karger.

Lewis, C. (1981). Skill in algebra. In J. R. Anderson (Ed.), Cognitive skills and their acquisition. Hillsdale, $\mathrm{NJ}$ : Erlbaum.

Lewis, C. (1987). Composition of productions. In D. Klahr, P. Langley, \& R. Neches (Eds.), Production system models of learning and development (pp. 329-358). Cambridge, MA: MIT Press.

MacLane, S. (1986). Mathematics: Form and function. New York: Springer.

Markman, E. M. (1978). Empirical versus logical solutions to part-whole comparison problems concerning classes and collections. Child Development, 49, 168-177.

Markman, E. M. (1990). Constraints children place on word meanings. Cognitive Science, 14, 57-77.

Metz, K. E. (1985). The development of children's problem in a gears task: A problem space perspective. Cognitive Science, 9, 431-472.

Moshman, D. (1990). The development of metalogical understanding. In W. F. Overton (Ed.), Reasoning, necessity, and logic: Developmental perspectives (pp. 205-225). Hillsdale, NJ: Erlbaum.

Neches, R., Langley, P., \& Klahr, D. (1987). Learning, development, and production systems. In D. Klahr, P. Langley, \& R. Neches (Eds.), Production system models of learning and development (pp. 1-53). Cambridge, MA: MIT Press. 
Newport, E. L. (1990). Maturational constraints on language learning. Cognitive Science, 14, 11-28.

Piaget, J. (1971). Biology and Knowledge. Chicago: University of Chicago Press.

Piaget, J. (1972). Essai de logique opératoire [Essay on the logic of operations] (2nd ed.). Paris: Dunod.

Piaget, J. (1976). The grasp of consciousness. Cambridge: Harvard University Press (Originally published 1974).

Piaget, J. (1977a). Conclusions générales [General conclusions]. In J. Piaget, Recherches sur l'abstraction réfléchissante, Vol. 2: L'abstraction de l'ordre et des relations spatiales (pp. 303-324). Paris: Presses Universitaires de France.

Piaget, J. (1977b). Essai sur la nécessité [Essay on necessity]. Archives de Psychologie, 45, 235-251.

Piaget, J. (1985). The equilibration of cognitive structures: The central problem of intellectual development. Chicago: University of Chicago Press. (Originally published 1975).

Piaget, J. (1987). Possibility and necessity, vol. 1: The role of possibility in cognitive development. Minneapolis: University of Minnesota Press (Originally published 1981).

Powers, W. T. (1973). Behavior: The control of perception. Chicago: Aldine. 
Rozin, P. (1976). The evolution of intelligence and access to the cognitive unconscious. In J. M. Sprague \& A. D. Epstein (Eds.), Progress in psychobiology and physiological psychology (Vol. 6). New York: Academic Press.

Simon, H. A. (1969). The sciences of the artificial. Cambridge, MA: MIT Press.

Smith, C., Carey, S., \& Wiser, M. (1985). On differentiation: a case study of the development of the concepts of size, weight, and density. Cognition, 21, 177-237.

Spelke, E. S. (1990). Principles of object perception. Cognitive Science, 14, 29-56.

Sternberg, R. J. (Ed.). (1984). Mechanisms of cognitive development. New York: Freeman. 
Thornton, S. (1987). Adaptive production systems as models of human development. In J. C. Rutkowska \& C. Crook (Eds.), Computers, cognition, and development: Issues for psychology and education (pp. 255-279). London: Wiley.

VanLehn, K. (1988). Toward a theory of impasse-driven learning. In H. Mandl \& A. Lesgold (Eds.), Learning issues in intelligent tutoring systems (pp. 19-41). New York: Springer Verlag.

Voelin, C. (1976). Deux expériences à propos de l'extension dans l'épreuve de la quantification de l'inclusion [Two studies concerning the extensions of the classes in the class-inclusion task]. Revue suisse de Psychologie, 35, 269-284.

Wallace, I., Klahr, D., \& Bluff, K. (1987). A self-modifying production system model of cognitive development. In D. Klahr, P. Langley, \& R. Neches (Eds.), Production system models of learning and development (pp. 359435). Cambridge, MA: MIT Press.

Wittgenstein, L. (1958). Philosophical investigations. New York: Macmillan. 